\title{
Ankle osteochondroma: a case report
}

Volume 9 Issue 2 - 2017

\section{Ana Costa Pinheiro, Bruno Pereira, João Melo, Daniel Freitas, Manuel Vieira Da Silva Servico de Ortopedia, Hospital De Braga, Braga, Portugal}

\section{Introduction}

The osteochondroma is a benign bone tumor surrounded by a cartilaginous capsule. ${ }^{1}$ Most osteochondroma is asymptomatic, being accidentally detected during radiographic examination. ${ }^{2}$ The osteochondroma usually reach the metaphysis of long bones and pelvis and are rarely located in the foot and ankle, except in the case of Multiple Hereditary Exostoses. ${ }^{3}$

Thus, its location on the ankle is rare, and very few cases are published in the literature. To date we have not found any ankle osteochondroma reported in Portugal. The aim of this paper is to present a case of distal tibia osteochondroma with more than 20 years of evolution, treated surgically.

\section{Case report}

The authors present the case of a female patient, 45 years old, with neoformation in the left tibia, with several years of evolution. It was a massive osteochondroma of the distal tibia involving the left tibioperoneal syndesmosis (Figure 1) and fibula deformity. The patient observed apparent increase in size in recent years with episodes of associated pain or discomfort in this location.

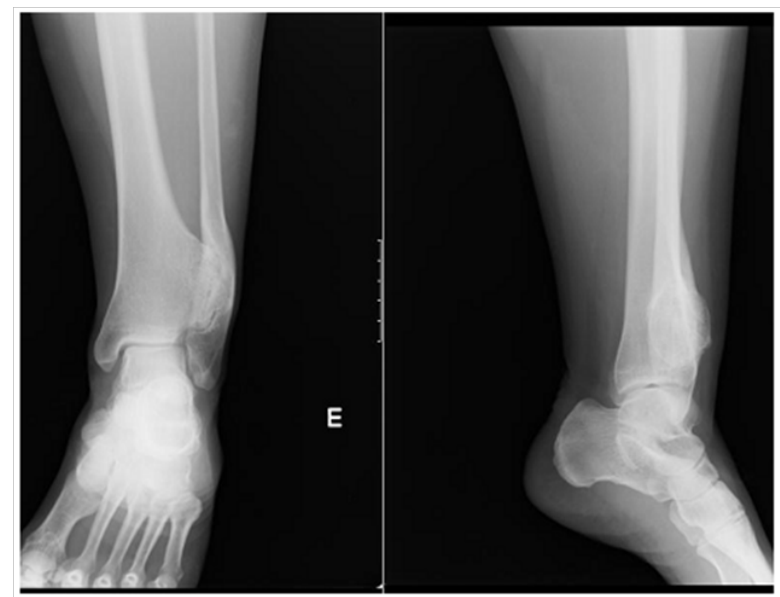

Figure I Left ankle X-Ray that demonstrates exostosis in the distal tibia, causing pressure and deformity in the fibula.

Physical examination revealed normal range of mobility and swelling of regular contours of the anterolateral region of the left ankle, hard, painless to palpation, without neurovascular compromise and without ankle instability. No other exostosis in the limbs was observed.

In addition to the X-ray of the left ankle, it was performed Computed tomography (CT) and preoperative Magnetic resonance imaging (MR) for a better definition of the lesion (Figures 2-3).

She was submitted to lesion excision and osteosynthesis with syndesmosis tibio-peroneal and fibula stabilization with plate and 2 trans-syndesmotic screws (Figure 4).
Correspondence: Ana Costa Pinheiro, Servico de Ortopedia, Hospital De Braga, Braga, Portugal,

Email ana.alexandra.pinheiro@gmail.com

Received:September 25, 2017 | Published: October 18, 2017

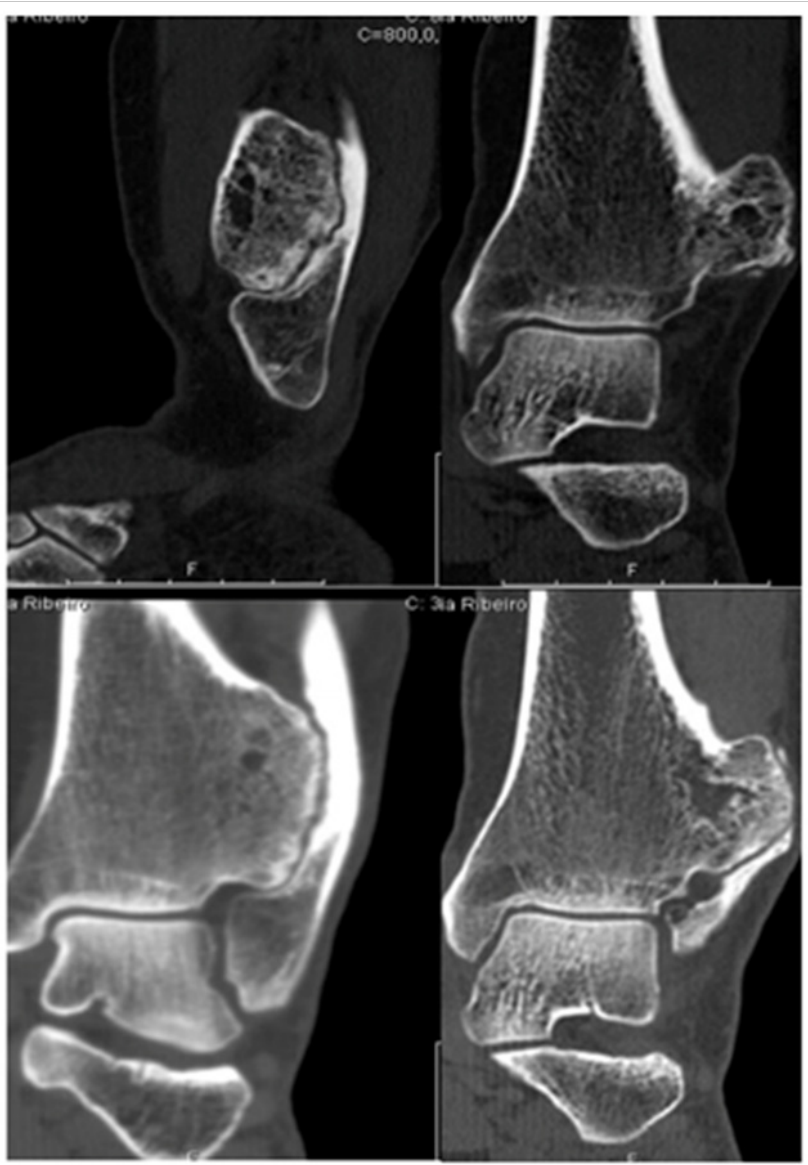

Figure 2 Preoperative TC, showing the lesion and fibula invasion.

Histopathological examination confirmed the diagnosis of osteochondroma. At 2 months after surgery it was performed the extraction of two trans- syndesmotic screws (Figure 5), and after 18 months it was removed all material of osteosynthesis (Figure 6). 


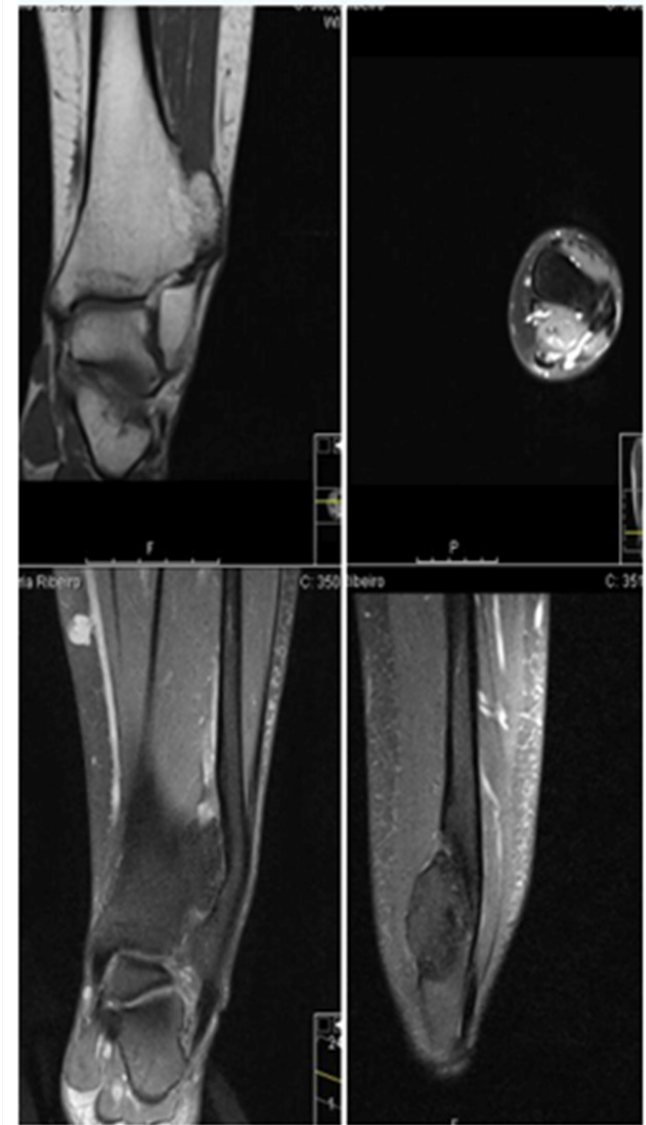

Figure 3 Preoperative MR, showing the lesion and fibula invasion.

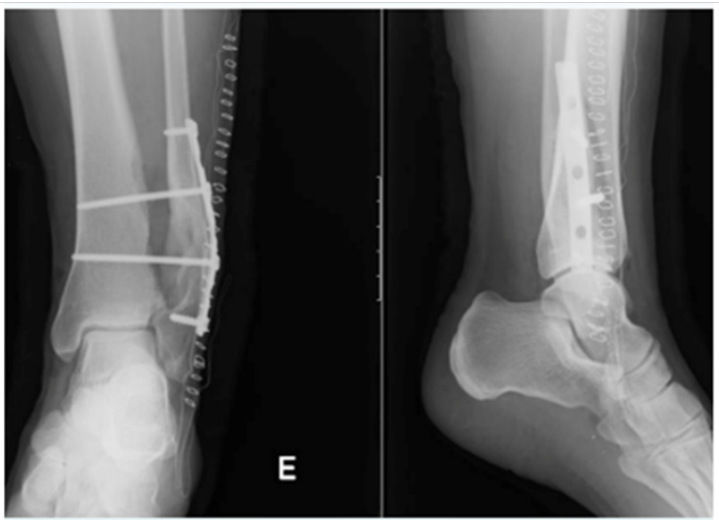

Figure 4 X-Ray post-excision of the lesion demonstrating osteosynthesis with plate and screws.

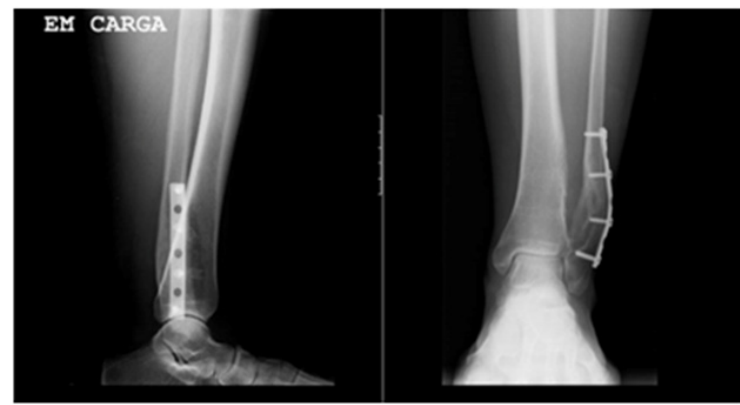

Figure 5 X-Ray after removing two trans-syndesmotic screws.
At 3 years after surgery, the patient shows a complete recovery, with full mobility and no residual pain and radiologically without evidence of recurrence (Figure 6).

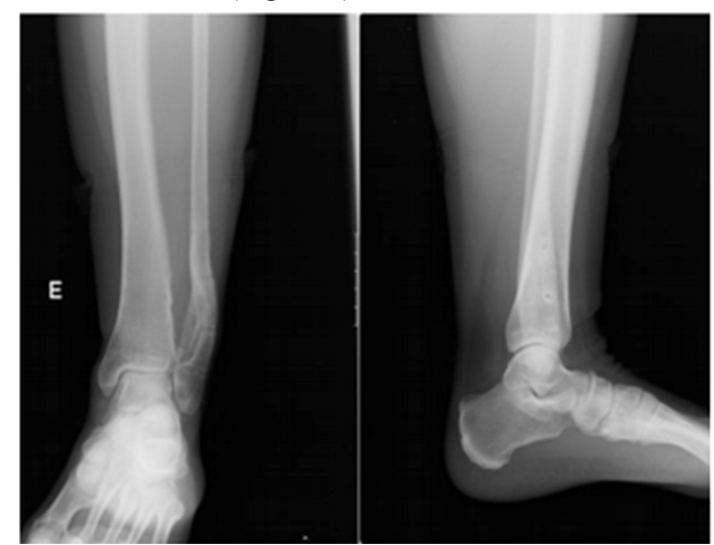

Figure 6 X-Ray after 3 years lesion excision.

\section{Discussion \& conclusion}

The osteochondroma discovered incidentally in asymptomatic patients are treated conservatively with follow-up. ${ }^{4-6}$ The patient should be informed of the rare possibility of malignant transformation $(<1 \%)$ and should be reevaluated if the injury becomes greater or more painful. ${ }^{7-9}$

Surgical resection is indicated in symptomatic patients due to irritation of the surrounding soft tissues; injury subject to minor trauma; injury with cosmetic deformity or potential damage to joints or surrounding neurovascular structures and lesions with features of malign transformation..$^{7-10}$

In the literature, there are described various surgical approaches: anterior, posterior and trans-peroneal approach associated with peroneal reconstruction. The anterior approach without fibular osteotomy, as performed in this case, is associated with lower morbidity after surgery..$^{10,11}$

Note: that there is little information about the clinical course of the ankle osteochondroma after its surgery, hence the need for a follow-up extended to these patients.

\section{Acknowledgments}

None.

\section{Conflicts of interest}

None.

\section{References}

1. Unni KK. Cartilagenous lesions of bone. J Orthop Sci. 2001;6:457-472.

2. Chin KR, Kharazzi FD, Miller BS, et al. Osteochondromas of distal aspect of tibia and fibula. Natural history and treatment. J Bone Surg Am. 2000;82(9):1269-1278.

3. Perez M, Mendozaa M, Bergua-Domingoa JM, et al. Osteochondromas around the ankle: Report of a case and literature review. International Journal of Surgery Case Reports. 2013;4:1025-1027.

4. Danielsson LG, El-Haddad I, Quadros O. Distal tibial osteochondroma deforming the fibula. Acta orthop Scand. 1990;61(5):469-470.

5. Southerland JT. Osteochondroma of distal tibia-A case study. J Am Podiatr Med Assoc. 1995;85(10):542-545. 
6. Krieg JC, Buckwalter JA, Peterson KK, et al. Extensive growth of an osteochondroma in a skeletally mature patient. A case report. $J$ Bone Joint Surg Am. 1995;77(2):269-273.

7. Mirra JM. Bone tumours, clinical, radiologic and pathologic correlation. Philadelphia, Lea and Febiger. 1989;2(4):1626-1660.

8. Galasso O, Mariconda M, Milano C. An enlarging distal tibia osteochondroma in the adult patient. $J$ Am Pediatr Med Assoc. 2009;99(2):157-161.
9. Matsumoto K, Sumi H, Shimizu K. Tibial osteochondroma causing foot pain mimicking tarsal tunnel syndrome: a case report. J Foot Ankle Surg. 2005;44(2):159-162.

10. Gupte CM, DasGupta R, Beverly MC. The transfibular approach for distal tibia osteochondroma: an alternative technique for excision. $J$ Foot Ankle Surg. 2003;42(2):95-98.

11. Wani IH, Sharma S, Malik FH, et al. Distal tibial interosseous osteochondroma with impending fracture of fibula - a case report and review of literature. Cases. 2009;J;(1):115. 